\title{
Penentuan Koordinat Titik pada Teknologi Garis dalam Grafika Komputer dengan Menggunakan Algoritma Line Equation
}

\author{
Mufadhol \\ Fakultas Teknologi Informasi dan Komunikasi \\ Universitas Semarang \\ Semarang \\ Telp. (024) 6702757 \\ mufadhol@usm.ac.id
}

\author{
Mohammad Sani Suprayogi \\ Fakultas Teknologi Informasi dan Komunikasi \\ Universitas Semarang \\ Semarang \\ Telp. (024) 6702757 \\ yogie@usm.ac.id
}

\begin{abstract}
Abstrak - Grafika Komputer atau computer graphics adalah bagian dari ilmu komputer yang berkaitan dengan pembuatan dan manipulasi gambar (visual) secara digital. Bentuk sederhana dari grafika komputer adalah grafika komputer 2D yang kemudian berkembang menjadi grafika komputer 3D. Pola penggambaran yang paling sederhana adalah dengan menggunakan titik pada teknologi garis. Algoritma Line Equation merupakan salah satu metode untuk menentukan lokasi koordinat titik pada teknologi garis dalam grafika komputer dengan cara menentukan nilai gradien garis serta garis yang berpotongan dengan sumbu $Y$, sehingga bisa mengetahui pixel yang akan menyala pada screen coordinate.
\end{abstract}

Kata Kunci - line equation, grafika komputer, screen coordinate

\section{PENDAHULUAN}

Grafika Komputer atau computer graphics adalah bagian dari ilmu komputer yang berkaitan dengan pembuatan dan manipulasi gambar (visual) secara digital. Bentuk sederhana dari grafika komputer adalah grafika komputer 2D yang kemudian berkembang menjadi grafika komputer 3D, pemroses atas citra (image processing), dan pengenalan pola (pattern recognition). Grafika komputer sering dikenal juga dengan istilah visualisasi data.Perbedaan antara world coordinate dengan screen coordinate membutuhkan suatu tampilan yang proporsional dalam merepresentasikan gambar pada layar penampil. Sistem kerja screen coordinate yang menggunakan pixel dengan cara mematikan dan menyalakan satu titik pada lokasi layar penampil memerlukan suatu metode untuk menentukan lokasi tersebut. Algoritma line equation merupakan salah satu metode untuk menentukan posisi pixel sebagai representasi titik untuk membuat suatu garis pada teknologi garis. Garis akan dimulai dengan titik awal (x1, y1) dan akan berujung pada titik akhir (x2, y2), sehingga posisi titik/pixel akan dapat diketahui dengan menghitung nilai y dengan cara menghitung gradien (m) serta menentukan nilai perpotongan garis dengan sumbu y (b). Keuntungan menggunakan algoritma dengan metode line equation adalah tidak perlu menghitung koordinat berdasarkan persamaan yang lengkap (menggunakan metode offset).

Sedangkan kerugiannya adalah adanya akumulasi round-off errors, sehingga garis akan melenceng darigaris lurus, selain itu operasi round-off juga menghabiskan waktu. Dengan melihat sulitnya perhitungan dan juga penentuan koordinat objek pada teknologi garis dalam grafika komputer, maka perlu adanya suatu media bantu untuk mempermudah perhitungan dan juga penentuan koordinat dengan menggunakan metode line equation.

\section{METODE PENELITIAN}

2.1 Metode Pengumpulan Data

a. Metode Studi Pustaka

Studi pustaka dilakukan dengan studi literatur atau membaca buku-buku, Internet, dan catatan-catatan yang menunjang penelitian penentuan titik pada grafika komputer berdasarkan algoritma line equation.

b. Metode Observasi

Observasi adalah teknik dimana peneliti mengamati objek atau hal-hal yang diperlukan dalam menghitung dan menentukan posisi pixel berdasarkan algoritma line equation.

\subsection{Metode Pengembangan Sistem}

Prototype paradigma adalah merupakan suatu metode pendekatan pengembangan atas rekayasa perangkat lunak, prototype paradigma dimulai Dengan pengumpulan kebutuhan dan perangkat lunak, mengindentifikasi segala kebutuhan yang diketahui, kemudian dilakukan perancangan kilat. Pendekatan prototype paradigma melewati tigaproses, yaitu pengumpulan kebutuhan, perancangan cepat, dan evaluasi prototype.

a. Pengumpulan Kebutuhan

Pada fase ini peneliti menentukan tujuan umum suatu teknologi garis, menentukan kebutuhan dalam perhitungan algoritma garis yang diperlukan dan gambaran bagian-bagian yang akan dibutuhkan dalam 
menentukan posisi pixel berikutnya berdasarkan algoritma line equation.

b. Perancangan Prototype

Perancangan dilakukan secara cepat dan pada fase ini, rancangan mewakili semua aspek software untuk menentukan posisi pixel dalam screen coordinate berdasarkan pada algoritma line equation, dan rancangan ini menjadi dasar pembuatan prototype.

c. Evaluasi Prototype

Peneliti mengevaluasi prototype yang sudah dibuat yaitu hasil perhitungan koordinat titik dengan menggunakan algoritma line equation dan digunakan untuk memperjelas posisi pixel dalam suatu software.

Perulangan ketiga proses ini terus berlangsung hingga semua perkiraan terpenuhi. Prototype dibuat untuk memastikan perhitungan dan untuk menentukan posisi titik dengan benar. Prototype yang dibuat agar dapat digunakan kembali untuk membangun software lebih mudah dengan hasil yang sesuai dengan perhitungan, sehingga penentuan lokasi titik bisa dilakukan lebih cepat berdasarkan algoritma line equation.

\subsection{Lokasi Penelitian}

Penelitian dilakukan di Fakultas Teknologi Informasi dan Komunikasi Universitas Semarang dengan sasaran pengguna hasil penelitian ini adalah mahasiswa Teknik Informatika dengam mata kuliah Grafika Komputer.

\section{HASIL DAN PEMBAHASAN}

Proses implementasi algoritma Line Equation menggunakan bahasa pemrograman PHP ditambah dengan library PHP-GD untuk menggambar garis. Program yang dibuat membutuhkan 2 inputan yaitu input titik awal dan titik akhir dimana nantinyaalgoritma Line Equation akan membantu dalam pembentukan garis. Proses perhitungan ditampilkan langkah demi langkah, dengan harapan akan mempermudah pemahaman terhadap algoritma ini.

Aplikasi ini dapatdiakses dengan mudah melalui alamat URL http://journal.usm.ac.id/garis/lines.php .

Form inputan membutuhkan 2 koordinat yang berfungsi sebagai penentuan titik awal dan titik akhir. Adapun implementasi form input dibuat sederhana dan dapat dilihat pada Gambar 1. Pada form input tersebut, pengguna diharuskan mengisi koordinat, pada contoh diisikan koordinat $(1,2)$ dan $(-2,-1)$. Kemudian untuk memulai proses perhitungan, selanjutnya adalah menekan menu Hitung!.

Saat menu Hitung ditekan, maka program akan memulai proses kalkulasi dengan berdasarkan algoritma Line Equation yang juga ditampilkan prosesnya untuk memperjelas proses perhitungannya seperti yang terlihat pada Gambar 2. Angka yang tertampil pada proses perhitungan itu muncul secara otomatis berdasarkan data pada variabel yang diinputkan.

\section{Penentuan Koordinat Titik pada Teknologi Garis}

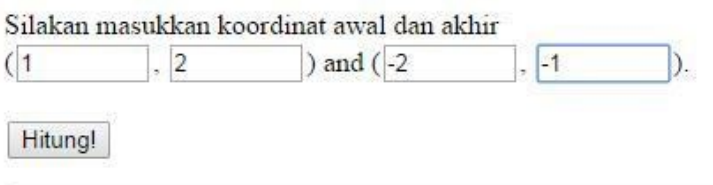

Gambar 1 Form Input

Proses Pencarian

Algoritma Line Equation menggunakan rumus dasar $y=a x+b$,

dimana a adalah gradient dan $b$ adalah titik perpotongan pada sumbu $Y$

yang melalui titik $(x 1, y 1)=(1,2)$ dan $(x 2, y 2)=(-2,-1)$

Gradient a adalah $a=\frac{y_{2}-y_{1}}{x_{2}-x_{1}}=\frac{-1-2}{-2-1}=1$

Perpotongan ditemukan melalui persamaan $a \cdot x_{1}+b=y_{1}$, atau $1 \cdot 1+b=2$

Maka, titik perpotongan $b$ adalah $b=y_{1}-a \cdot x_{1}$, atau $b=2-1 \cdot 1=1$

$y=(1) x+(1)$

Gambar 2 Proses Perhitungan Line Equation

Selanjutnya, setelah diketahui persamaan yang menentukan posisi garis, maka langkah berikutnya adalah menggambar garis dengan memanfaatkan library PHP-GD supaya terlihat posisi garis yang diinginkan. Hal ini dapat terlihat pada Gambar 3 di bawah ini .

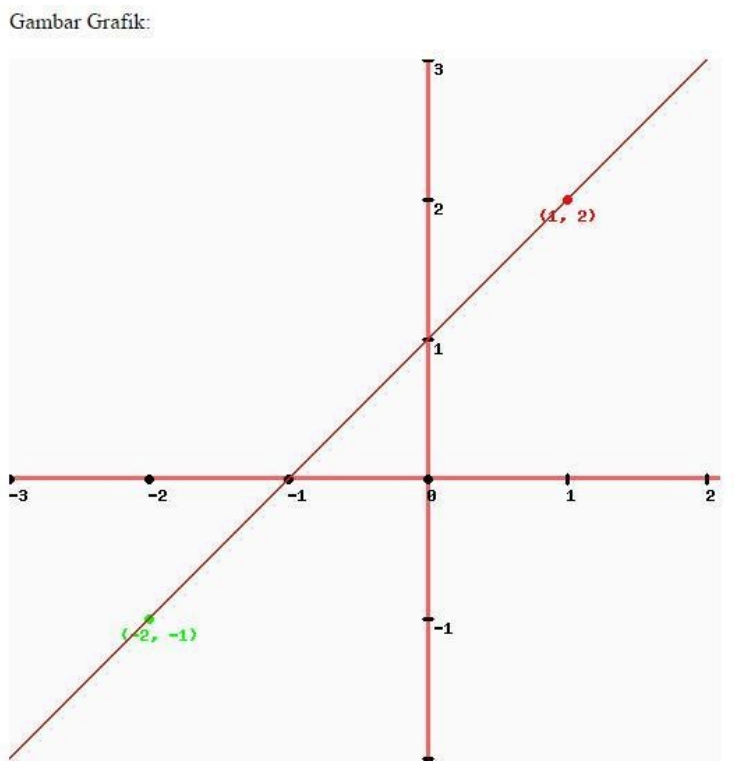

Gambar 3 Gambar Grafik Hasil

Adapun untuk menangani kelemahan algoritma perhitungannya yang tidak mengijinkan inputan dengan koordinat titik $X$ yang sama, maka diberikan notifikasi persamaan tidak dapat tercipta akibat nilai X sama, kemudian gambar grafik akan membantu untuk menjelaskan kesalahan, seperti yang terlihat pada Gambar 4 . 


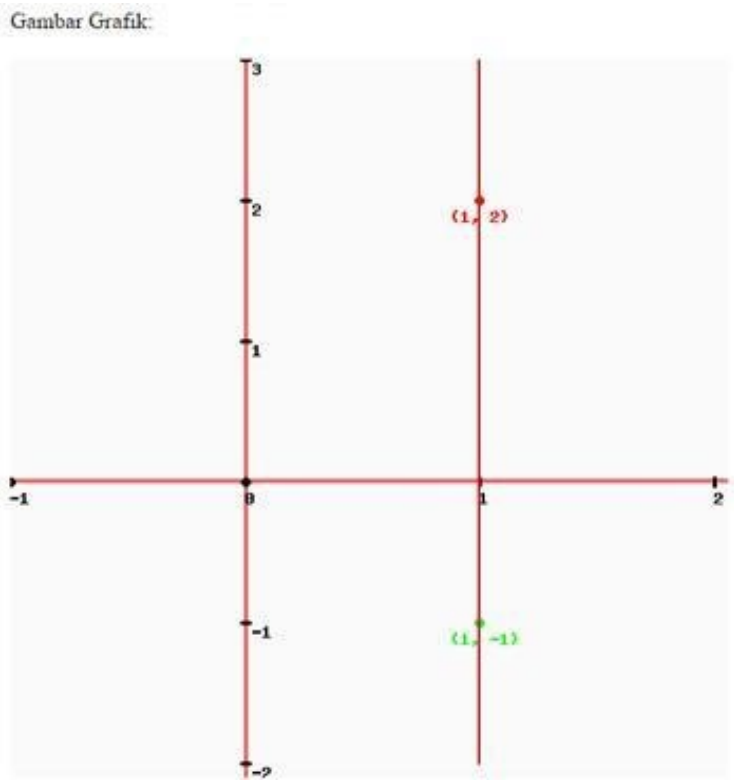

Gambar 4. Error Bila Nilai X Sama

\section{KESIMPULAN}

a. Algoritma line equation dapat digunakan untuk menentukan garis yang berada pada titik awal dan titik akhir.

b. Algoritma tidak dapat digunakan apabila titik x1 dan x2 bernilai sama.

\section{REFERENSI}

[1] HUGHES, J. F., FEINER, S. K., FOLEY, J. D.,

[2] AKELEY, K., MCGUIRE, M., DAM, A. V. \& SKLAR, D. F. 2013. Computer graphics: principles and practice, Boston, Addison Wesly.

[3] NUGROHO, E. 2005. Teori dan Praktek Grafika Komputer, Yogyakarta, Graha Ilmu.

[4] SUTOPO, A. H. 2002. Pengantar Grafika Komputer, Yogyakarta, Gava Media. 
